E. Reichardt, Bestimmung kleinster Mengen Arsen, Blei, Kupfer im Harn. 291

Botaniker wohlbekannte unangenehme Eigenschaft, im Herbar beim Trocknen schwarz zu werden. Es lag daher der Gedanke nahe, zu untersuchen, ob vielleicht das Rhinanthin in dieser Gruppe weiter verbreitet ist. Ich habe daher von den Arten, die ich in hiesiger Flora erlangen konnte, Samen gesammelt und untersucht.

Alectorolophus major Rchb. (die Stammform von A. hirsutus.), Alectorolophus minor Wimm. und Grab., Melampyrum cristatum L., Euphrasia Odontites L., Pedicularis palustris L. geben die Reaction auf Rhinanthin in übereinstimmender Weise; einige kümmerliche Früchte von Bartschia alpina L., die ich einem in meinem Herbarium befindlichen Exemplar entnahm, ebenso. Euphrasia officinalis L. gab die Reaction auch, doch war die Färbung, auch mit Salzsäure stets eine entschieden blaue. Pedicularis silvatica $\mathrm{L}$. ergab die Reaction gar nicht. Es dürfte nicht uninteressant sein, auch andere dahin gehörige Species, z. B. von Melampyrum, Pedicularis und Euphrasia zu untersuchen. -

Ludwig führt für die eigenthümliche Färbung des Brodes durch Melampyrum ein altes Zeugniss an, das des Hieronymus Pragus. Ebenfalls besprochen findet sie sich im Kräuterbuch des Dr. Jacob Theodor Tabernaemontanus, der darüber folgendermaassen schreibt:

„Wann der Kühweitzen unter den rechten Weitzen, Speltz und ander Korn kommet, und damit gemahlen wird, wie dann solches offt in dem Westerich und Land zu Lotthringen geschicht, so wird das Brot so davon gebacken wird, gantz braunroht, gleich wie auch um Dusa, Widersdorff und den andern umliegenden $\mathrm{Or}$ ten, das Brot davon blauschwartz wird, wie ich solches offtermal wie auch andre an gemeldten Orten ohne einigen Schaden und Verletzung genossen habe und ist sonst ein sehr gutes überaus wohlgeschmacktes Brot." -

\title{
Bestimmung kleinster Mengen Arsen, Blei, Kupfer u. dergl. im Urin.
}

Von E. Reichardt in Jena.

Diese Bestimmungen wurden von mir wiederholt im Interesse der Heilkunde ausgeführt, namentlich um den Grad einer lang- 
samen Vergiftung zu ermessen, wie sie durch Einathmen von Arsendämpfen oder Arsenverbindungen eintreten können. Es gelang dabei, diese Vergiftungen durch das Auftreten des Arsens im Urin nachzuweisen, z. B. in Folge der Bewohnung von Zimmern mit arsenhaltigen Farben, Tapeten u. dergl.

Die sonst übliche Zerstörung der organischen Substanz mittelst Chlor ist hierbei gänzlich unnöthig und sogar zu vermeiden, um Arbeiten zu ersparen und Einwände, wie man sie leicht aufzustellen pflegt bei dem Aufsuchen so kleinster Mengen von Substanz. Nicht nur Arsen, sondern auch Blei, Wismuth, Antimon, Kupfer, Quecksilber habe ich bei entsprechenden Krankheiten im Urin nachweisen können, unmittelbar gefällt durch Schwefelwasserstoff.

Man säuert den Urin mit wenigen Tropfen Salpetersäure an und leitet hierauf etwa $1 / 2$ bis 1 Stunde einen lebhaften Strom von gewaschenem Schwefelwasserstoffgas hindurch, so dass die Flüssigsigkeit mit diesem Gase übersättigt ist, lässt etwa 24 Stunden verschlossen stehen und filtrirt dann ab. Man verwendet hierzu etwa 1-2 Liter Urin und erwärmt denselben vorher wenig in einer Kochflasche, welche dann sofort zum Einleiten von $\mathrm{H}^{2} \mathrm{~S}$ dient.

Nach 12-24 stündigem Stehen der mit $\mathrm{H}^{2} \mathrm{~S}$ übersättigten Flüssigkeit war es mir nie möglich, noch weitere Fällungen der schon genannten Metalle zu beobachten.

Bei Prüfungen auf Blei, Wismuth, Kupfer, Antimon verbrenne ich das vollständig getrocknete Filter und schmelze die kohlige Asche mit einem Gemische von Soda und etwas Salpeter auf der Kohle. Die geringsten Spuren dieser Metalle erseheinen dann nach dem Schlämmen im Mörser, sobald man die nöthige Vorsicht, wie üblich, anwendet.

Bei Prüfung auf Arsen wird sofort nach dem Filtriren des mit Schwefelwasserstoff gesättigten Urins das Filter mit Bromwasser behandelt, welches $\mathrm{As}^{2} \mathrm{~S}^{3}$ zersetzt und das Arsen als $\mathrm{As}^{8} \mathrm{O}^{5}$ in Lösung bringt. Durch schwaches Erwärmen der verdünnten Lösung entfernt man das freie Brom und kann dann sofort die von mir angegebene Wasserstoffentwickelung mit vorgeschlagener Silberlösung (d. Zeitschr. Bd. 217. S. 1) in Anwendung bringen, oder auch die bromhaltende Lösung mit $\mathrm{H}^{3} \mathrm{~N}$ übersättigen und mit Magnesiamischung versetzen, worauf dann, selbst noch bei $1 / 10$ Millig. $\mathrm{As}^{2} \mathrm{O}^{3}$, deutlich sichtbar die arsensaure Ammoniakmagnesia auskrystallisirt. 
Bei so kleinen Mengen Arsen, wie sie unter den angedeuteten Verhältnissen im Urin anfzutreten pflegen, tritt allerdings die Magnesiareaction oft nicht mehr bemerkbar hervor, so dass man von vornherein dieselbe unterlässt. Giebt man aber die durch Brom erhaltene Lösung von $\mathrm{As}^{2} \mathrm{O}^{5}$ in den kleinen Wasserstoffentwickelungsapparat mit vorgeschlagener Silberlösung, so zeigen sich diese kleinsten Mengen Arsen noch dadurch aus, dass in der GasEinleitungsröhre in der Silberlösung unten am Ende ein Silberspiegel sich anlegt, von der Farbe der bekannten Arsenflecken nach dem Verfahren von Marsh. Wiederholte absichtliche Vergleichsversuche haben mir die Richtigkeit des Ergebnisses bestätigt und waren für den behandelnden Arzt ein sehr willkommener Aufschluss über die vorher doch nur geahnte Ursache der Krankheit.

Uebersättigt man die Silberlösung dann mit Bromwasser, das Filtrat von $\mathrm{AgBr}$ mit $\mathrm{H}^{3} \mathrm{~N}$ und fügt dann Magnesiamischung za, so gelingt bei aufmerksamen Suchen es selbst bei änsserst kleinen Mengen von Arsen, einzelne Krystalle der arsensauren Ammoniaktalkerde zu finden. Sicher bleiben dieselben bei dem Filtriren auf dem Filter und entwickeln dann bei dem Vorkommen dieses letzteren den eben so beweisenden Knoblauchsgeruch.

\section{Ueber rechtsdrehende zuckerfreie Harne.}

Von Dr. A. Bornträger in Marburg.

Vor einigen Jahren hatte ich Gelegenheit zwei Harne zu untersuchen, die deutlich rechts drehten, ohne dass diese Rotationen durch Zuckergehalt verursacht wurden. Die Harne stammten von zwei in einer Entwöhnungskur begriffenen Morphiophagen her, denen vor einigen (3 und 8) Tagen die letzte Dosis Morphium verabfolgt worden war. Die Excrete besassen normales Aussehen, während die an den vorhergegangenen Tagen gelassenen durch Gallenfarbstoff dunkel gefärbt gewesen waren. Die Rotationen betrugen $+0,4$ and $+0,6$; dieselben verschwanden durch Bleiessigzusatz s of ort, waren somit jedenfalls nicht durch Zucker bedingt (vergl. meine früher ${ }^{1}$ angeführten Versuche über das Verhalten

1) Archiv d. Pharm. 1880. Bd. 216. S. 415 u. f. 